\title{
The Role of Ethical Perceptions in Consumers' Participation and Value Co-creation on Sharing Economy Platforms
}

\author{
Waqar Nadeem ${ }^{1} \cdot$ Mari Juntunen ${ }^{1} \cdot$ Nick Hajli $^{2} \cdot$ Mina Tajvidi $^{3}$
}

Received: 11 February 2019 / Accepted: 11 October 2019 / Published online: 29 October 2019

(c) The Author(s) 2019

\begin{abstract}
Consumers' participation on sharing economy platforms is crucial for the success of the products, services, and companies on those platforms. The participation of consumers enables companies to not only exist, but also to create value for consumers. The sharing economy has witnessed enormous growth in recent years and consumers' concerns regarding the ethics surrounding these platforms have also risen considerably. The vast majority of the previous research on this topic is either conceptual and focused on organizational aspects, or only discusses privacy and security issues, thus providing a very limited scope of discussion. Therefore, drawing on the marketing and business ethics literature, the present study takes into account a multidimensional view of ethical issues surrounding consumers' participation on sharing economy platforms. Findings reveal that privacy, security, shared value, fulfillment/reliability and service recovery are the strongest determinants of consumers' ethical perceptions. These aspects strongly predict the consumers' value co-creation intentions. Consumers' participation also predicts their intention to engage in co-creating value, but this effect is stronger with the mediating role of the consumer's ethical perceptions. The theoretical and managerial implications are also discussed.
\end{abstract}

Keywords Sharing economy $\cdot$ Marketing ethics $\cdot$ Value co-creation $\cdot$ Service dominant logic

\section{Introduction}

Uber is a popular sharing economy platform (SEP) that connects consumers with reliable, convenient and safe transportation service providers. Uber is an online-mediated platform, and it collects the personal information of consumers, including phone numbers, email addresses, the location they sign up from and their full-names. Almost 100 million people use Uber, and given its popularity, like other online SEP platforms, such as Airbnb, Facebook, and Lyft, it has privacy and security checks in place. However, recently a data breach of 57 million users exposed all the personal information of Uber's customers to hackers. Uber has silently paid a "bug bounty" of \$100,000 to hackers to shore up

Waqar Nadeem

waqar.nadeem@oulu.fi

1 Department of Marketing, Management and International Business, Oulu Business School, University of Oulu, Oulu, Finland

2 School of Management, Swansea University, Swansea, UK

3 Newcastle University, Newcastle upon Tyne, UK the leak and a $£ 385,000$ fine to the UK government for the data breach. A total of 3 million UK based consumers were affected. Uber started to monitor user accounts for fraud only after 12 months had passed since the breach and did not notify any consumers whose personal information had been leaked (Statistia 2019; Macduffie 2017; TheGuardian 2018).

The aforementioned example demonstrates some of the ethical issues concerning sharing economy platforms. The sharing economy refers to the "acquisition or distribution of a resource coordinated by people for a fee or other types of compensation" (Belk 2014). In other words, sharing economy enables people to share their underutilized inventory through fee-based sharing (Zervas et al. 2017), that is, to rent their possessions for someone else for a limited time (Mittendorf 2016; Teubner and Flath 2019). Sharing economy researchers rightly point out that the act of sharing is not new and communal ways of life and bartering systems have long been known and used before (Cheng et al. 2018; Ertz et al. 2016; Sundararajan 2016). Only recently, has the term "sharing economy" been adapted to describe an emerging new culture of sharing. This culture involves people who share their belongings with others through online sharing economy platforms (SEPs) (Bucher et al. 2016). Through 
SEPs, consumers can gain temporary access to a product or service owned by someone else (Mittendorf 2016; Teubner and Flath 2019), after which the possession has to be returned to the owner in a pre-determined condition in order for the sharing deal to be complete. Often, the owner, i.e., the provider, is a consumer, reflecting the nature of consumer-to-consumer $(\mathrm{C} 2 \mathrm{C})$ business. This changes the role of companies such as Uber and Airbnb to serve as liaisons to make exchanges for money or other compensation between individuals who are strangers most of the time. This clearly shows that SEPs fundamentally differ from traditional business-to-consumer (B2C) focused online selling or e-commerce, in which ownership is transferred from the firm to the service provider and consumer. Consumers have been very enthusiastic to adopt the services offered by SEPs such as Uber, Airbnb, and Lyft (Zervas et al. 2017) and millions of people are taking an active part in SEPs constituting a profitable trend. For instance, the total revenues of the five largest SEPs in 2014 were US\$ 15 billion and are expected to reach US\$ 335 billion by 2025 (PWC 2015).

In essence, SEPs bring people together to participate and create value through their connections and experiences (Perren and Kozinets 2018), and thereby SEPs are valuable tools for marketers. Interaction between service provider and consumer is typically essential in order to conduct a business deal via SEPs. For instance, a service provider has to comply the requests of consumers in order to secure a business transaction. Consequently, the role of interaction through SEPs differs markedly from that taken via conventional e-commerce platforms, where no interaction between the seller and the buyer is required; in other words, the online platform covers the entire process of the ownership transfer (Mittendorf 2016). In such online settings where the buyer and seller have no experience of each other, platform mediation plays a huge role in enhancing trustworthy behavior leading to exchange (Perren and Kozinets 2018). SEPs are based on the principle of information sharing, and this requires consumers to input detailed personal information, which at times has been used for non-intended commercial purposes (Dillahunt and Malone 2015). Even the best known and historically respected companies have suffered from ethical lapses in the past 3 years. These include: Facebook in terms of data protection and privacy, Wells Fargo concerning consumer deception, BestBuy concerning data breaches (Laczniak and Murphy 2019), and Uber which has allegedly cheated its drivers by rounding off fees to the nearest dollar in favor of the company (see, e.g., Newcomer 2017; TheGuardian 2018). This means that on the one hand, consumers perceive participation in SEPs to be more economical, enjoyable and convenient (Zach et al. 2018). However, on the other hand, consumers may associate SEPs with privacy and security risks, which might deter their participation on such platforms and decrease their willingness to share their personal information on SEPs (Lutz et al. 2018). In the light of the aforementioned issues, it becomes paramount for the sharing economy service providers to understand consumers' ethical perceptions of their platforms. This will enable SEPs to prioritize their resources and reduce the potential risks.

Research into SEPs has only just begun to emerge and individual level studies have not received much scholarly attention (Zach et al. 2018). The existing research on SEPs covers topics such as why people participate in collaborative consumption (Hamari et al. 2016) and what makes people use SEPs again (Möhlman 2015). Research that touches upon ethics has revealed that perceived privacy and security risks are inhibiting factors against using SEPs (Zach et al. 2018), yet several authors have strongly emphasized the need to further explore the ethical aspects related to SEPs (Perren and Kozinets 2018; Sutherland and Jarrahi 2018). In particular, two major research gaps exist in the extant literature. First, researchers generally agree that consumers need to perceive an online platform as ethical. Consumer's ethical perceptions refer to perceptions of responsibility and integrity of the company behind the online platform. These especially concern "an attempt to deal with consumers in a secure, confidential, fair and honest manner that ultimately protects consumer's interests" (Roman 2007, p. 134). Researchers have concluded that ethical perceptions of the consumers' in online environment are a multidimensional construct consisting of various dimensions-such as privacy, security, fulfillment/reliability and non-deception (e.g., Roman 2007), service recovery (Agag 2016; Cheng et al. 2014) and shared value (e.g., Agag 2016). However, to the best knowledge of the authors of this study, no research has examined consumers' ethical perceptions in the context of SEPs. Because Mittendorf (2016) argues that findings from the e-commerce context cannot be assumed for the sharing economy, as these two entities are fundamentally different, and due to the important and timely role of SEPs in consumer behavior, it is essential that the ethical perceptions of SEPs be examined.

Second, although the extant research on SEPs offers important contributions, a general model describing the role of ethical perceptions remains absent. This model should include the embedded role of consumer participation and the co-creation of value on online platforms. Previous e-commerce research recognizes both antecedents to ethical perceptions, such as consumers' Internet expertise (Roman and Cuestas 2008) and the consequences of ethical perceptions such as relationship quality (Agag 2019), word-of-mouth (Roman and Cuestas 2008), satisfaction, and repurchase intention (Agag et al. 2016). However, these studies do not help to understand how ethical perceptions relate to consumer participation and their value co-creation intentions on SEPs. Creating such a model would clarify the role of the 
ethical perceptions of consumers towards SEPs and would thus offer a platform for further studies. Related to this, although research has extensively advanced our understanding of the concept of co-creation in the last decade (Grönroos 2008; Payne et al. 2008; Zwass 2010), value co-creation on SEPs is under researched (Camilleri and Neuhofer 2017; Zhang et al. 2018). Furthermore, negligible consideration has been given to the notion of consumers' participation in value co-creation activities (Martinez-Cañas et al. 2016).

Against this backdrop, the purpose of the current study is to develop a theoretical framework to describe the role of consumers' ethical perceptions in relation to their participation and intention to co-create value on SEPs, and to test the framework empirically. To achieve this, we endeavor to answer the following research questions: (1) What are the dimensions of consumers' ethical perceptions of SEPs? and (2) What is the role of ethical perceptions in relation to consumer participation and value co-creation intentions on SEPs? We specifically focus on the transactional issues between consumers and SEPs, and not on broader institutional characteristics, such as sustainability, corporate social responsibility and so forth. Theoretically, the current study provides a profound understanding of a multidimensional construct of consumers' ethical perceptions of SEPs and its role in relation to consumers' participation and value co-creation intentions on SEPs. Analyzing the empirical data $(n=453)$ from SEP users using structural equation modeling (SEM) confirms the essential role of consumers' ethical perceptions as a mediating factor between consumer participation and the intention to co-create value on SEPs. The current study contributes to the existing literature on the sharing economy as one of the pioneering studies examining whether and how consumers' participation on an SEP influences the consumers' value co-creation intentions. The study incrementally adds to the growing body of knowledge on this subject. Additionally, the study provides insights for managers into how consumers' ethical perceptions are formed, and which ones are important. This provides advice for practitioners on how to enhance consumer participation and value co-creation on SEPs.

\section{Theoretical Background}

\section{Consumers' Ethical Perceptions of SEPs}

Marketing ethics is broadly defined as the systematic study of how moral standards are applied to behaviors, decisions and institutions (see e.g., Laczniak and Murphy 2019). The seminal work by Bartels (1967) provided the first conceptualization of factors which influence marketing ethics in decision making. Scholars became more interested in the topic and contributed steadily to issues of unethical marketing such as deceptive advertising, dangerous products, and misleading prices. Practitioners became more interested in marketing ethics in the 1980s and professional organizations and companies started to adopt certain codes of ethics in their operations (Agag 2019). Since then, marketing ethics has become a well-established field (Ferrell et al. 2015; Gaski 1999; Schauster and Neill 2017), and review studies have indicated different domains of marketing ethics (see e.g., Laczniak and Murphy 2019; Schlegelmilch and Oberseder 2010). Our aim is not to add to the existing body of knowledge on ethical marketing domains such as sustainability or corporate social responsibility. The aim of this study is to focus on transaction related ethical issues concerning SEPs.

It is widely recognized among researchers that ethical aspects differ in offline and online environments. For instance, ethical transgressions are more likely to happen on online platforms than in face to face transactions (Citera et al. 2005), and consumer's ethical evaluations are formed in different ways on online platforms and in offline settings (Roman 2007). The Internet in general is often seen as an environment for unethical behavior (Freeston and Mitchell 2004; Hajli 2018). For instance, e-commerce platforms (Bart et al. 2005), social commerce platforms (Nadeem et al. 2017), and SEPs (Sutherland and Jarrahi 2018) are all technology mediated platforms and the ethical concerns of consumers are highly common on these platforms. Sharing personal information online makes consumers vulnerable to both accidental and intentional harm by other consumers (Dinev and Hart 2006; Malhotra et al. 2004).

There is a plethora of studies related to e-commerce ethics (see e.g., Agag 2019; Citera et al. 2005; McIntyre et al. 1999; Miyazaki and Fernandez 2001; Roman 2007). Marketing ethics has also been discussed in the literature on social commerce (see, e.g., Featherman and Hajli 2015; Hajli and Lin; Hajli 2018). Several authors have called for systematically investigating ethical issues related to the advancements in technological platforms (Laczniak and Murphy 2019), and this study seeks to empirically examine them.

SEPs differ from traditional e-commerce/other online platforms markedly, which creates novel ethical challenges, specifically in terms of interaction. In the conventional e-commerce industry, interaction between buyers and sellers remains an exception (Mittendorf 2016): the online platform covers the entire process of the ownership transfer, allowing consumers to purchase goods even without the seller's prior agreement. SEPs facilitate interaction between service providers and consumers that is fundamental to conducting a business deal. For example, service providers have to comply with the requests of consumers in order to secure business transactions. Therefore, SEPs foster consumer-to-consumer (C2C) interaction before any business deal can take place. In this sense, unlike in e-commerce, private individuals are able to monetize 
their underused or idle personal resources at a large scale, as micro-entrepreneurs or domestic entrepreneurs (Stabrowski 2017) via SEPs. SEPs only act as intermediaries or enablers fostering interactions and facilitating transactions between consumers and service providers by helping them locate each other in situations in which they may otherwise have been difficult to locate. Therefore, platform mediation in sharing economy is crucial to reducing the impact of uncertainties between service providers and consumers. Hence, the SEPs are charged with the added responsibility of providing an ethical environment for both consumers and service providers in order for transactions to take place.

Given the nature of SEPs, it may become impossible for consumers to make transactions without providing personal information. Becoming a service provider through an SEP and marketing one's possessions effectively to other consumers requires making a large amount of information publicly available to others even before the transaction occurs. This typically requires revealing personal data (Slee 2017; Sundararajan 2016; Teubner and Flath 2019). Such personal information is published through vivid online profiles including self description in terms of personal profiles, real addresses, real names, real phone numbers, and photographs of one's residence among other important personal details (Dambrine et al. 2015; Ma et al. 2017). Because the successful marketing of possessions only takes place if the information provided is real and indicates trustworthiness (Huang and Liu 2010). In addition, information about one's whereabouts, information about the layout of one's home, such as where the living room, spare guest room or bedroom are, is freely circulated amongst acquaintances, colleagues, and co-workers (Teubner and Flath 2019). This kind of information could remain hidden in traditional e-commerce settings. Yet, not only the SEP service providers but also the consumers are vulnerable. For instance, consumers enter a huge amount of personal data with SEPs, including sensitive information such as addresses, passwords, and credit card information (Acquisti et al. 2016; Dakhlia et al. 2016; Teubner and Flath 2019). Consumers' personal information is processed further by SEPs to match them with service providers, for setting prices, and monitoring overall behavior to devise better services (Einav et al. 2016). A little negligence, mischief, mistake, or misconduct in the form of server corruption, identity theft or data breach from the SEPs' side can be of huge concern for consumers (see e.g., TheGuardian 2018). Therefore, it becomes crucial for the SEPs to convey a sense of security to the consumers present on such platforms. Hence, consumers' ethical perceptions of SEPs cover both their own personal data as well as the ethical behavior of other consumers and the SEP. However, only a few studies have examined privacy related issues in a sharing economy (see e.g., Dillahunt and Malone 2015; Hawlitschek et al. 2016; Lutz et al. 2018; Teubner and Flath 2019), and research related to other ethical aspects remains absent.

Researchers have studied consumers' ethical perceptions in online settings. In such settings, privacy and security have consistently been identified as the two main ethical concerns (Roman and Cuestas 2008). Privacy deals with uncertainty linked to personal information that is provided on online platforms, and the risk of such information being exposed to unintended individuals or parties (Bart et al. 2005). Privacy on SEPs refers to the protection of personally identifiable information and protecting it from unauthorized/unwanted use by other consumers (Lutz et al. 2018). Personal information leakage can lead to unsolicited contact from other companies or individuals, unauthorized sharing of that information, or the undisclosed tracking of transactions (Miyazaki and Fernandez 2001). Therefore, consumers' concerns about their control of their personal information in terms of subsequent use and disclosure are related to privacy concerns. Security pertains to the notion of uncertainty regarding online platforms that could lead to incurring monetary losses during interaction on those platforms (Roman 2007). Security issues could arise in the form of data breaches because of lapses in security on SEPs or other online platforms (see, e.g., Cadwalladr and Graham-Harrison 2018; Smith 2016) resulting in the loss of personal, financial, or transactionoriented information. Although the role of privacy on SEPs (Lutz et al. 2018) has attracted some research interest, in the sharing economy context, even these issues are underexplored (Sutherland and Jarrahi 2018). In the sharing economy context, security provided by an SEP refers to the safety of online transactions, including protection from malware and unauthorized access to personal financial information and the safety of payment methods.

Contemporary researchers have also proposed other ethical issues which are potentially important and need to be taken into account in online environments. These include fulfillment/reliability, non-deception, service recovery, shared value, sales behavior, and communication (Agag 2019; Cheng et al. 2014; Roman 2007). Along with privacy and security, we focus on the first four of these issues, as these specifically relate to SEPs. Including these constructs adds multidimensionality, wholeness and greater complexity to measuring ethics than using a unidimensional approach to measure consumers' ethical perceptions of SEPs.

Non-deception refers to the notion that SEP service providers should not engage in fraud by relying on manipulative, or deceptive practices to make consumers purchase their offerings and make transactions (Limbu et al. 2011). On SEPs, this kind of fraud involves the unreliable delivery of goods/services and even purposeful misrepresentation. However, the concept has not received much attention in the sharing economy literature (Roman 2010). Fulfilment/ reliability assert the degree to which consumers believe that 
they are able to place an order as accurately as possible on an online platform (Parasurman et al. 2005; Wolfinbarger and Gilly 2003). This relates to the accurate display and description of the services offered, prompting for order confirmations, and providing good tracking services. The service should be as it has been presented; for instance, if an Airbnb room looks luxurious in the pictures but is not the same in reality, Airbnb has failed to fulfill its promise reliably. Shared value measures the extent to which consumers and service providers believe the degree to which both have common values regarding which goals, behaviors or policies are right or wrong, important or un-important (Morgan and Hunt 1994). For instance, seeking the permission of the consumer on an SEP for sending the promotional material represents the shared values of SEPs and consumers. Service recovery deals with the course of actions an online platform service provider takes in case of service delivery failure (Gronroos 1988). This situation occurs when the failure of on an online service provider results in a perceived loss to the consumer. At this point, the online service provider compensates for the damage by providing some gain or means of recovery to reduce the damaging effect to the business and to reassure the consumer. A recovery has to be made so that the consumer reaches a point of satisfaction (Sparks and McColl-Kennedy 2001).

Before introducing our research model for the structure and the role of consumers' ethical perceptions of the SEPs, we review the literature on consumers' participation in SEPs and value co-creation. These offer both the essential concepts for our research model and the underlying explanations linking the concepts.

\section{Consumers' Participation on SEPs}

Traditional models of consumption related to e-commerce websites are being substituted by sharing economy platforms as a viable alternative in terms of servitization (see e.g., Cusumano 2015; Hellwig et al. 2015). Sharing economy or consumer-to-consumer (C2C) platforms are two-sided markets, the main entities in which are consumers and service providers. The success of such SEPs critically hinges on the activity of both aforementioned entities (Teubner and Flath 2019). SEPs exist because of the active online participation of consumers. In other words, SEPs will cease to exist if nobody participates on them. Consumers' participation on SEPs and the creation of successful SEPs can be major challenges.

From a theoretical viewpoint, consumers' participation on SEPs is embedded in the social psychological stream of uses and gratifications theory (UGT) (Katz et al. 1973) and in our context seeks to explain the relationship between the online platform and active consumer participation. Theoretically, consumers' participation can be explained by UGT (Raacke and Bonds-Raacke 2008). UGT is one of the most commonly adapted theories of media use and it facilitates the understanding of media use and its wide application (Dwyer et al. 2007). Internet users seek and explore various gratifications on media platforms resulting in finding reasons to continuously use and participate on such platforms (Limayem and Cheung 2011). UGT has a strong base in the media domain, and owing to its strong significance and theoretical foundation, it provides a strong basis in sharing economy contexts. For instance, the rise of SEPs has sparked the interest of researchers to better understand UGT applications in various contexts (Bucher et al. 2016).

In the context of social networking sites, users are generally devoted, engaged, participative and highly motivated to create user generated content and spending time on these platforms (Krause et al. 2014). In the same vein, taking into account the importance of consumer participation on SEPs, examining this from a specific UGT perspective is crucial. On SEPs consumers can actively participate and the term "active" is strongly linked with UGT which includes selecting content and actively interpreting it (Khan 2017). On the contrary, Livingstone (2004) has argued that active online users can be self-directed, selective producers and consumers of the information at the same time. Some consumers present on an SEP might just be there for the sake of reading reviews, comments, posts from other consumers, or looking at photographs, thus consuming information only, rather than producing it. Consumers themselves might choose a passive role by not participating in discussions or contributing anything to the SEP.

Consumer's participation on SEPs refers to an effort to achieve value co-creation through required but voluntary participation in service production and delivery processes on SEPs (Chae and Ko 2016; Kamboj et al. 2018). Previously, participation has also been referred to as 'interaction', i.e., the degree to which online members actively participate in the online platform's activities. If consumer participation on an online platform is established, it provides an added assurance that the online platform will be successful and will remain a success (Koh and Kim 2004). UGT has been used comprehensively to underline the consumers' motivation to participate on SEPs, yet less attention has been paid to how participation is comprised of various dimensions, especially on SEPs. Kamboj and Rahman (2017) differentiate three types of participation: informational participation, actionable participation, and attitudinal participation. Information participation is defined as "the degree to acquire information and fulfill general interests that a consumer possesses in the product or service"; actionable participation refers to "the degree to which consumers participate in SEP activities frequently, and depicts the level of interaction between consumers on the SEPs"; and attitudinal participation deals with "the psychological tendency to evaluate the performance of 
an SEP with a favorable or unfavorable assessment or some degree of positive or negative attitude towards the product or service, or platform in general" (Kamboj and Rahman 2017, p. 437).

Before testing whether these three forms of participation constitute consumers' participation also on SEPs and how consumer participation relates to consumers' ethical perceptions of SEPs, we will review the literature on value co-creation.

\section{Value Co-creation on SEPs}

In the sharing economy, the role of other consumers on SEPs becomes prominent when seeking advice and interactive discussions can lead to useful solutions/answers. This encourages consumers to participate more actively (Huang et al. 2013) and gives an opportunity for the SEP to enhance positive and repeated interactions, thus creating more value for the SEP. An illustrative example of value co-creation could be where on one side consumers are willing to pay a price for a convenient, economical, alternative for transportation, e.g., a taxi service. On the other side, there are service providers (drivers) who are willing to drive consumers and charge a fee for their services. Therefore, as the number of consumers increase, they will attract more service providers (drivers) to join the platform and vice versa. For instance, Uber creates a platform that facilitates consumers and service providers by creating an easy access platform and matching the demand and supply sides for transportation, thus creating value for everyone participating on the SEP (Sayar 2015). For companies to remain competitive and gain competitiveness, value co-creation has recently emerged as a major strength (Merz et al. 2018; Zwass 2010), and is thus the approach we adopt in our view.

According to service dominant (SD) logic (Vargo and Lusch 2004, 2008; Williams and Aitken 2011) companies are increasingly relying on consumers to co-create value and this understanding has led companies to utilize consumers and their experiences to create value as they design and develop products and services (Prahalad and Ramaswamy 2004). Prahalad and Ramaswamy (2004) have termed value co-creation as a holistic management strategy which brings distinct agents together producing valued outcomes. Companies utilize a value co-creation approach frequently in order to gain a competitive advantage and build a strong corporate reputation and brand value (Cova and Dalli 2009). Value co-creation emphasizes the joint efforts by consumers, companies and other agents and means that mutual dependence and reciprocity are crucial for defining the interdependent roles associated with the production of value creation and service it provides (Vargo et al. 2008). Furthermore, SD-logic asserts that, services and not goods are the unit of exchange and the mutual actions of the consumer(s) and service provider(s) result in value co-creation. For efficient service delivery, consumers must learn to maintain, use, repair and adapt offerings to their usage situations, unique needs and behaviors (Vargo and Lusch 2004, 2008).

Value co-creation as a concept can also be viewed through the theoretical lens of new product development, which asserts giving a more active role to consumers, and companies are increasingly engaging consumers in the development of their services and products. As consumers are proactive on SEPs, they are able to participate in the design, testing, service conceptualization, product/service marketing and support specialization (Nambisan and Nambisan 2008; OHern and Rindfleisch 2010). In order to enhance value co-creation, companies also offer more tailored goods and services to consumers to encourage their participation (Bendapudi and Leone 2003; Firat and Venkatesh 1993). This, along with the essential role of consumer participation as described above, is a crucial basis for SEPs to exist.

Despite the substantial importance of SEPs, little consideration has been given to measuring consumers' value co-creation intentions on such platforms in general, and in relation to the consumers' ethical perceptions particularly. To address this shortcoming, we next introduce our research model.

\section{Research Model and Hypotheses}

\section{Research Model}

Building on the aforementioned theoretical discussions, we propose a general and encompassing theoretical model which highlights the role of consumers' ethical perceptions as a mediating factor between consumers' participation and their value co-creation intentions on SEPs as shown in Fig. 1. Integrating the concepts has the potential to provide a new direction to marketing ethics research specifically in sharing economy literature.

The main concept of the model concerns the consumers' ethical perceptions. This is embedded in the literature on marketing and business ethics (Agag 2019; Bush et al. 2000; Cheng et al. 2014; Laczniak and Murphy 2019; Roman and Cuestas 2008). Consumers' ethical perceptions are considered as a multidimensional construct consisting of six subdimensions: privacy, security, non-deception, fulfillment/ reliability, shared value, and service recovery. Secondly, the consumers' participation on SEPs has been developed on the basis of UGT (Kamboj and Rahman 2017; Katz et al. 1973). Consumers' participation is hypothesized to be a multidimensional construct, comprised of three sub-dimensions: informational participation, actionable participation and attitudinal participation. Thirdly, the concept of consumers' value co-creation intentions have been developed on 


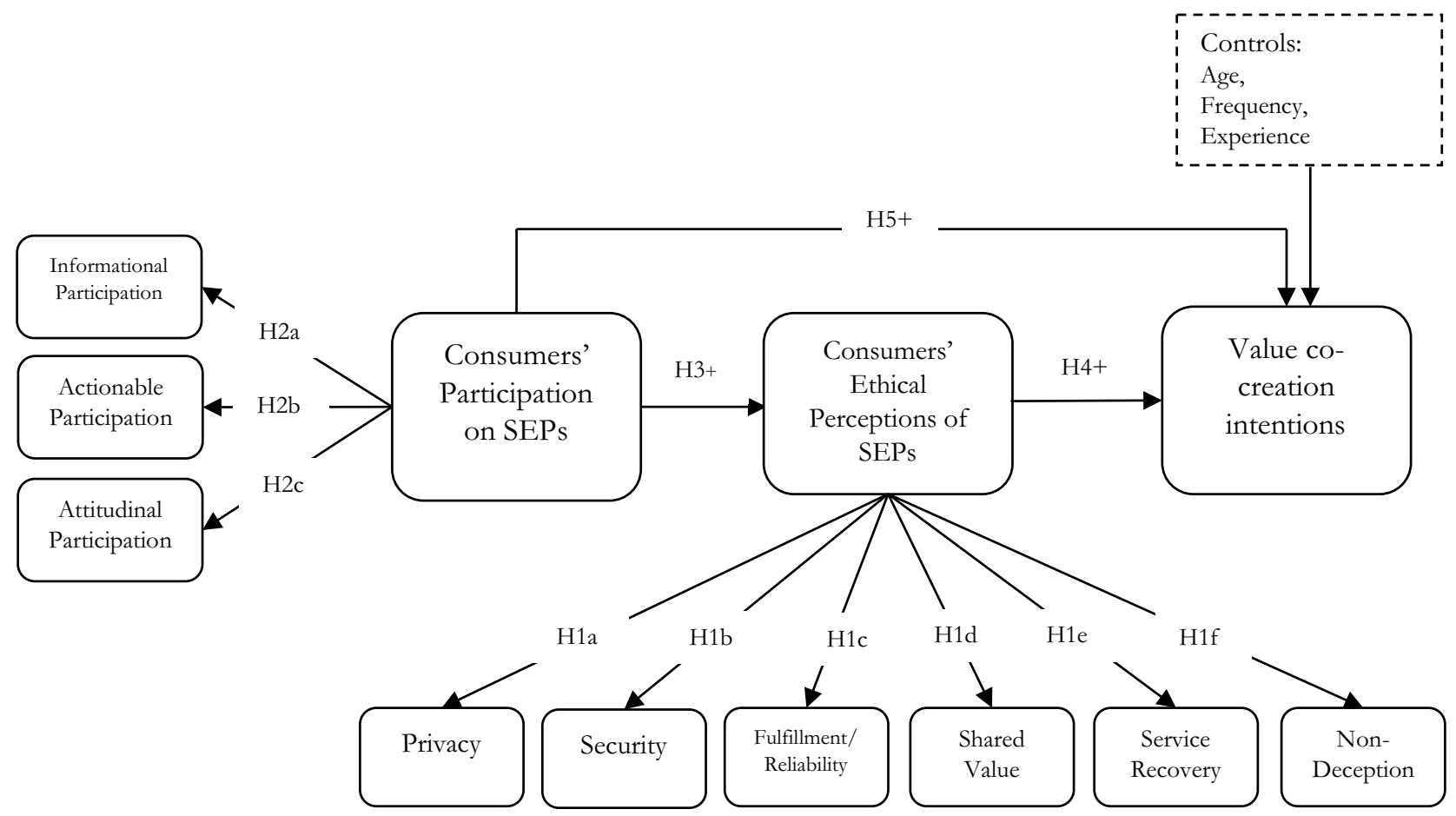

Fig. 1 Research Model

the basis of the literature on service dominant logic (Vargo and Lusch 2004, 2008, 2016; Vargo et al. 2008). The integrations between the three concepts are based on the well documented theoretical foundations provided by previous studies (see, e.g., Abel and Murphy 2008; Williams and Aitken 2011). In the following section, the hypotheses of the current study are discussed.

\section{Hypotheses Development}

Ethics is an abstract and broad concept. More specifically business ethics are broadly referred to as a business action that can be categorized as right or wrong (e.g., Barry 1979; Roman and Cuestas 2008). This definition is highly abstract in nature and several authors have termed ethics as a multidimensional and complex construct (Agag et al. 2016; Agag 2019; Cheng et al. 2014; Roman and Cuestas 2008). For example, Reidenbach and Robin's (1990) business ethics scale is constituted of three factors-moral equity, contractualism, relativistic — comprising of eight semantic differential items. In addition, in an attempt to assess consumers' perceptions of retailers' ethical actions, McIntyre et al. (1999) identified two factors: honesty and fairness.

E-commerce researchers have proceeded in a slightly different direction. Roman (2007) examined consumers' perceptions regarding an online retailer and considered ethical perceptions to be a second-order construct comprising of four factors: privacy, security, non-deception and fulfillment/reliability. Similarly, Cheng et al. (2014) devised a scale for assessing consumers' perceived ethics of e-commerce websites. The scale was named "eTransethics" and their second-order construct consisted of five factors including sales behavior, privacy, security, fulfillment and service recovery. In addition, Agag et al. (2016) identified several dimensions of e-retailing ethics from the consumer's perspective and termed the second-order construct as buyer perceptions of sellers' ethics (BPSE). The dimensions of BPSE include: privacy, security, reliability, non-deception, service recovery and shared value. The synthesis of all the aforementioned studies reveal that ethics is a complex phenomenon and can be measured through multiple dimensions.

Although many researchers agree on the most important constructs, there is no consensus on the number of dimensions that make up the construct of consumers' ethical perceptions in the context of e-commerce. Additionally, no research has examined consumers' ethical perceptions at SEPs. Based on the conceptual and theoretical foundations provided by the above studies the current study considers consumers ethical perceptions of SEPs (CEPSEP) as a higher order abstract latent factor with manifestations of six factors. In other words, CEPSEP is a second-order construct and harnesses the most relevant six factors from the extant research as the sub-constructs of: privacy, security, non-deception, fulfillment/reliability, service recovery and shared value. Hence, the following hypothesis is proposed: 
H1 Consumers' ethical perceptions of sharing economy platforms (CEPSEP) is a second-order construct composed of six dimensions: (a) privacy; (b) security; (c) fulfillment/ reliability; (d) shared value; (e) service recovery; and (f) non-deception.

Consumer participation refers to the required but voluntary participation on SEP for the sake of value co-creation in service production (Chae and Ko 2016; Kamboj et al. 2018). Traditionally, consumer participation has been measured on a single item scale (Algesheimer et al. 2005). Some studies have measured consumer participation as a unidimensional construct comprised of two items (Kang et al. 2014; Wang et al. 2015). However, recently, a multidimensional perspective of consumers participation has been taken into account (Carlson et al. 2018; Chae et al. 2015; Chae et al. 2016; Kamboj and Sarmah 2018).

Consumers can participate in SEPs for different reasons, for instance, to obtain information about products or services, and they may develop a positive or negative psychological tendency based on the SEP's performance. As described in the theoretical section, these reasons are termed as informational participation, actionable participation and attitudinal participation, respectively, in the extant research (Kamboj and Rahman 2017). By building on the theoretical foundations provided by Kamboj and Rahman (2017), who examined customer participation in online travel communities, we consider the consumers' participation in SEPs as an abstract and a multidimensional construct, comprised of three factors: informational participation, actionable participation and attitudinal participation. The three factors are manifestations of the consumer's participation. Hence, we hypothesize:

H2 Consumers' participation on SEPs is a second-order construct composed of (a) informational participation; (b) actionable participation; and (c) attitudinal participation.

Consumer participation can create a greater sense of comfort with the SEP and reduce the ethical concerns associated with it. For instance, Koh and Kim (2004) argue that participation includes disseminating ideas, sharing knowledge, and providing emotional support to other consumers on an online platform. Consumers share information related to their experiences of products or services for which the online platform has been developed, and more participation on the online platform will lead to more sharing of experiences and expectations (Lamb and Kling 2003) and this ultimately results in a positive behavioral outcome.

Consumer's participation may lead to determining the actual ethical issues associated with SEPs (e.g., security or privacy of the platform) which often are exaggerated by the service providers (Miyazaki and Fernandez 2001). There is an enormous data stream available on SEPs and the personal information of consumers is exposed to service providers, at times raising ethical concerns. More participation on SEPs can also make consumers more aware of how their data is collected and processed further by the SEP. Hence, an increase in participation on an SEP can increase the positive ethical perceptions of the SEP. As consumers participate more on an online platform, they acquire more information which reduces the uncertainty aspect in making transactions (Pai and Tsai 2011). Hence it is hypothesized:

H3 Consumers' participation on SEPs positively affects the consumers' ethical perceptions of sharing economy platforms (CEPSEP).

Koh and Kim (2004) have asserted that the number of people participating on SEPs determines the long-term success of an online platform. Thus, online platforms try their utmost to encourage consumers to be highly involved in the platform for the sake of enduring relationships (Algesheimer et al. 2005). This high degree of involvement is dependent on the consumers' positive ethical perceptions of the online platform (Roman and Cuestas 2008). In addition, Williams and Aitken (2011) argue that consumers' participation in co-creation activities is enhanced when businesses behave in accordance with values that motivate consumers. In the current era, ethics can be termed as one such value (MartinezCanas et al. 2016).

According to Prahalad and Ramaswamy (2004), cocreation is the process of engaging consumers in creating value, and consumers will not engage if they have ethical concerns. Broadly, value co-creation reflects a participatory culture, in which consumers seek the opportunity to contribute to their virtual worlds, enabling companies to assess consumer insights regarding their brands (Ind et al. 2013). Furthermore, Veloutsou and Moutinho (2009) argue that consumers' participation on an online platform can be either positive or negative for the company, and this might affect the company's reputation and image. Therefore, the consumers' value co-creation intentions can be hugely affected by the consumers' ethical perceptions of the seller. Hence, we hypothesize:

H4 Consumers' ethical perceptions of sharing economy platforms (CEPSEP) positively affect their value co-creation intentions.

Additionally, several authors have suggested that consumer participation on online platforms can affect brand with regard to value co-creation (Martinez-Cañas et al. 
2016), loyalty, equity, trust (Chae and Ko 2016; HennigThurau et al. 2010). Companies benefit from consumer participation on SEPs as they get to know more about consumers' needs, wants, and preferences concerning products or services. Companies may also harness shared knowledge in the form of posts, reviews, and comments by consumers in order to create more value (Baldwin et al. 2006). As SEPs are built on the same principles as social commerce platforms, thus consumer participation on SEPs becomes an important element of value co-creation (Hajli et al. 2017).

Previously, consumer participation has been found to positively influence satisfaction and loyalty (Pai and Tsai 2011). In addition, previous studies have shown that consumer participation on online platforms results in value creation (Schau et al. 2009), consumer and brand relationships (Carlson et al. 2018), value co-creation involving ethical products and services (Martinez-Canas et al. 2016) and branding cocreation (Kamboj et al. 2018). Hence, we hypothesize:

H5 Consumers' participation on SEPs positively affects the consumers' value co-creation intentions.

\section{The Data}

\section{Data Collection}

An online survey was employed to collect data from consumers concerning the world's leading sharing economy platforms, including Uber, Airbnb, Lyft, HomeAway, Indiegogo, Zipcar, and Kickstarter. At times, researchers conducting consumer surveys relying on college student samples have been criticized due to their inherent limitations (see, e.g., Peterson and Merunka 2014). Therefore, we relied on Amazon's MTurk as it represents external and internal validity (see, e.g., Horton et al. 2011; Smith et al. 2016). The sample for the current study were consumers who rely on and are involved with the aforementioned SEPs. Using MTurk, almost 500 respondents were recruited at a cost of $0.5 \$$ each. Previous researchers have found MTurk results to be comparable in quality with other data collected from online and offline domains (see, e.g., Buhrmester et al. 2011; Mason and Suri 2012). To focus on the relevant respondents and to ensure the quality further, the data was initially screened and it was ensured that only consumers who actually relied on SEPs were taken into account for further analyses. A sample profile is shown in Table 1.

\section{Measurement}

All of the measures in the current study were adapted from the previous literature and a seven-point Likert scale was used (ranging from $1=$ "Strongly disagree" to $7=$ Strongly
Table 1 Sample profiles

\begin{tabular}{ll}
\hline & $\%$ \\
\hline Gender & \\
Male & 50.6 \\
Female & 49.4 \\
Age & \\
GenZ (Less than 19 years) & 0.2 \\
GenY (19-37 years) & 71.1 \\
GenX (37-54 years) & 28.7 \\
(Frequency)How often do you use SEPs? & \\
Daily & 5.3 \\
Weekly & 33.3 \\
Monthly & 34.7 \\
Quarterly & 17.9 \\
Once in 6 months & 6.0 \\
Once in an year & 2.9 \\
(Experience) For how long have you been using the SEPs? & \\
1 year & 7.7 \\
2 years & 20.5 \\
3 years & 28.0 \\
4 years & 21.9 \\
5 years & 10.8 \\
Whears & 11.0 \\
Uber & \\
Airbnb & 55.84 \\
Lyft & 13.46 \\
KickStarter & 12.36 \\
Others ${ }^{\mathrm{a}}$ & 4.64 \\
\hline & 13.7 \\
\hline
\end{tabular}

${ }^{a}$ Others include, homeaway, patreon, snapgoods, zipcar etc

agree"). To make it appropriate for our research context, that is, sharing economy platforms, we reworded the items to a small extent. The consumers' participation on an SEP was classified as an exogenous independent variable. This was further measured by three sub variables, informational participation, actionable participation and attitudinal participation and the items for these variables were adapted from Kamboj and Rahman (2017) and Kamboj et al. (2018). The items for six sub-variables (privacy, security, shared value, fulfillment/reliability, service recovery, non-deception) of consumers' ethical perceptions of SEPs were adapted from studies by Agag et al. (2016), Agag (2019), Roman (2007) and Cheng et al. (2014). The items for value co-creation intentions were obtained from Ramaswamy and Ozcan (2016) Schau et al. (2009), and Tajvidi et al. (2018). 


\section{Normality and Measurement Validation}

To satisfy the criterion of multivariate normality, several tests were conducted in a systematic way to fulfill the criteria of covariance-based structural equation modeling (CB-SEM) (Hair et al. 2017). The first step involved screening the data and checking for unengaged responses, such as when evidenced by giving the exact same response for every question. Eventually 19 cases were removed. Secondly, to ensure the data quality further, we ran a test for normality and outliers, i.e., the Mahalanobis distance test and influential multivariate outliers with values less than $P<0.001$ were identified. The correlations between variables for 28 cases were significantly different or abnormal compared to the rest of the dataset, and were removed. Thirdly, all the values were below +3 and -3 , so as evidenced by the skewness and kurtosis test, there was no indication of any non-normal distribution issues. Fourthly, to identify the outliers, the data was checked using Cook's distance test and the factor scores were found to be far below 0.1 (Cook 1977). Lastly, a multicollinearity check revealed the scores of the variance inflation factors (VIFs) were 1.445, and were below the threshold value of 3. Additionally, the tolerance values were greater than 0.1 for all constructs. The multivariate normality tests enabled us to ensure that there was no departure of the data from normality. Eventually a dataset of $n=453$ was retained to further perform the analysis.

\section{Non-Response and Common Method Bias}

The online survey link was open for respondents for seven days. The desired number of responses $(n=500)$ was obtained within the given timeframe and no reminders were sent to the respondents, which means that the data was obtained from one group within a certain timeframe. Consequently, non-response bias, which refers to comparing early and late responses, is a non-issue in the current study.

However, the problem of common method bias can occur when the data is collected from the same population at the same time and might influence the validity of the study (Podsakoff et al. 2003). To address the issue of common method bias, we applied Harman's single factor test. An exploratory factor analysis was run by constraining the number of factors to 1 and using an un-rotated solution. In the current dataset, it was observed that the maximum variance explained by a single factor is 33.972 . Therefore, it can be asserted that the current dataset does not suffer from the common method bias issue because the variance explained by a single factor is approximately $34 \%$, which is less than the threshold value of $50 \%$. No single factor surpassed the threshold value of 50\%. In addition, Pavlou et al. (2007) suggested that no correlations between the constructs should be above 0.9. If there is an issue of common method bias, then the correlations between the constructs would be significantly higher $(r>0.90)$. The results in the current study reveal that no correlations were above 0.78 . Consequently, common method bias was seen as a non-issue in this study.

\section{Data Analyses and Results}

The IBM SPSS Amos version 24 software package was employed to analyze the data. The reliability and validity of the constructs was examined first through an exploratory factor analysis and then with confirmatory factor analysis tests (Anderson and Gerbing 1988; Fornell and Larcker 1981). After a careful analysis of the items contributing to the poor fit of the model, factors with cross loadings and small loadings were deleted accordingly. Furthermore, criteria for modification indices and standardized residual covariances were also taken into account to retain the final items. In the confirmatory factor analysis, non-deception had a nonsignificant relationship with the main construct, which were the consumers' ethical perceptions and was thus excluded from further analyses. All the retained items and constructs show good internal consistency (Table 2).

The psychometric properties of each construct were assessed, and each measurement scale was assessed as reliable: the Cronbach's alphas ranged higher than the 0.70 threshold suggested by Nunnally (1978). The lowest Cronbach's alpha value in our study for the construct was 0.816 , thus there were no issues in meeting the reliability criterion. Goodness of fit statistics of the measurement model revealed an acceptable fit (Table 3).

\section{Validity and Reliability}

As evidence of convergent validity, all the loadings were above 0.7. In addition, as evidence of discriminant validity (Hu and Bentler 1999) there were no strong cross loadings in an exploratory factor analysis of the data except for actionable participation, informational participation and attitudinal participation. These items were further treated as higher order factors. Moreover, all the factors related to consumers' ethical perceptions of sharing economy platforms were treated as higher order factors, which is well supported by the documented literature (Cheng et al. 2014; Roman 2007). In addition, there were no loadings in the factor correlation matrix which were greater than 0.7, and all the AVE values were above 0.5 (Table 4 ). 
Table 2 Constructs and measurement items

Constructs and measurement items

Standardized Mean $\mathrm{SD}^{\mathrm{a}} \quad \mathrm{CA}^{\mathrm{a}}$ loading $(t$

value)

Consumers' Participation on SEPS

Informational participation

I frequently provide useful information online to the other members

I post messages and provide responses online in the SEP frequently

Actionable Participation

I actively participate online in the SEP's activities

I spend a lot of time online in participating with the SEP's activities

\begin{tabular}{llll} 
& & & 0.855 \\
$0.821(22.02)$ & 4.35 & 1.893 & \\
$0.911(. s t d)$ & 3.98 & 1.998 & \\
& & \multicolumn{2}{c}{0.928} \\
$0.927(. s t d)$ & 3.89 & 1.933 & \\
$0.935(32.01)$ & 3.64 & 1.965 & \\
& & & 0.910 \\
$0.960(. s t d)$ & 4.96 & 1.568 & \\
$0.869(22.45)$ & 5.12 & 1.566 &
\end{tabular}

I think participating in this SEP would be good for me

I think participating in this SEP would be beneficial for me

$0.869(22.45) \quad 5.12 \quad 1.566$

Consumers' Ethical Perceptions of Sharing Economy Platforms(CEPSEP)

Privacy

Without the consent of consumers, this SEP will not use personal information for purposes other than for
the original transactions

This SEP guarantees that personal information of consumers will be handled in accordance with a third party's privacy-protection regulations and has acquired authentication knowledge

This SEP will not apply special technology to collect and analyze the internet behavior and shopping habits of consumers without their consent

Security

The e-payment system of this SEP is safe and verified

This SEP guides consumers to correct and safe payment steps

Fulfillment/Reliability

Consumers receive the correct products/service items and their quantities ordered online

Consumers receive products/services that are ordered online, matching the description on this SEP

This SEP guarantees that products/services ordered online are authentic and not imitations

Shared value

$0.817(. \mathrm{std})$

$5.02 \quad 1.440$

$0.835(19.33) \quad 5.02 \quad 1.420$

$0.818(18.88) \quad 4.81 \quad 1.507$

The SEP respects our business values

The SEP and I have mutual understanding of each other's business values

The SEP sticks to highest level of business ethics in all its transactions

Service recovery

This SEP responds to customer complaints promptly

This SEP tells consumers what to do when online transactions cannot be completed

Service failure is not neglected by this SEP and it is promptly dealt with via a reasonable service-recovery measure

Value Co-Creation Intentions

I am willing to provide my experiences and suggestions when my friends through my favorite SEP want my advice on buying something from a sharing economy platform

I am willing to buy the products/services of SEP recommended by my friends through my favorite sharing economy platform

I will consider the buying experiences of my friends through my favorite SEP when I want to go for a service in a sharing economy platform

$S D$ standard deviation, $C A$ cronbach's alpha

${ }^{\text {a }}$ Scales adapted from the mentioned authors in the text and altered in the context of sharing economy platforms

Table 3 Goodness of fit indices

\begin{tabular}{lllllllll}
\hline SRMR & NFI & CFI & GFI & PClose & Chi square $\left(\chi^{2}\right)$ & $d f$ & $P$ value & RMSEA \\
\hline 0.084 & 0.920 & 0.945 & 0.879 & 0.000 & 651.294 & 219.00 & 0.000 & 0.066 \\
\hline
\end{tabular}

SRMR standardized root mean square residual, NFI normed fit index, CFI comparative fit index, GFI goodness of fit index, $d f$ degrees of freedom, RMSEA root mean square error of approximation 
Table 4 Validity and reliability of measures

\begin{tabular}{llllllll}
\hline & CR & AVE & MSV & MaxR(H) & COCRE & PARCP & CEPSEP \\
\hline COCRE & 0.878 & 0.706 & 0.517 & 0.887 & 0.841 & & \\
PARCP & 0.899 & 0.751 & 0.251 & 0.936 & 0.428 & 0.867 & \\
CEPSEP & 0.902 & 0.650 & 0.517 & 0.909 & 0.719 & 0.501 & 0.806 \\
\hline
\end{tabular}

$C R$ composite reliability, $A V E$ average variance extracted, $M S V$ maximum shared variance, $\operatorname{Max} R(H)$ maximal reliability, COCRE value co-creation intentions, $P A R C P$ consumers' participation on sharing economy platforms, CEPSEP consumers' ethical perceptions of sharing economy platforms

Table 5 Goodness of fit indices of causal model

\begin{tabular}{llllllll}
\hline SRMR & NFI & CFI & GFI & Chi square $\left(\chi^{2}\right)$ & $d f$ & $P$ value & RMSEA \\
\hline 0.085 & 0.907 & 0.940 & 0.877 & 760.656 & 285 & 0.000 & 0.061 \\
\hline
\end{tabular}

SRMR standardized root mean square residual, NFI normed fit index, CFI comparative fit index, GFI goodness of fit index, $A G F I$ adjusted goodness of fit index, $d f$ degrees of freedom, RMSEA root mean square error of approximation

Table 6 Path estimates

\begin{tabular}{lllll}
\hline Relationships & Hypotheses & Std. estimates $(t$ value $)$ & $P$ value & \\
\hline PARCP $\rightarrow$ CEPSEP & H3+ & $0.502(8.984)$ & 0.000 & Supported \\
$\mathrm{CEPSEP} \rightarrow$ COCRE & H4+ & $0.666(10.905)$ & 0.000 & Supported \\
$\mathrm{PARCP} \rightarrow$ COCRE & $\mathrm{H} 5+$ & $0.109(2.237)$ & 0.025 & Supported \\
Age $\rightarrow$ COCRE & Control variable & $0.020(0.508)$ & 0.611 & Not Supported \\
Frequency $\rightarrow$ COCRE & Control variable & $0.038(0.992)$ & 0.321 & Not Supported \\
Experience $\rightarrow$ COCRE & Control variable & $0.064(1.693)$ & 0.090 & Not Supported \\
\hline
\end{tabular}

PARCP consumers' participation on sharing economy platforms, CEPSEP consumers' ethical perceptions of sharing economy platforms, COCRE value co-creation intentions

\section{Invariance Tests}

For the multigroup analysis (male vs female) a configural invariance test was conducted. An adequate goodness of fit was shown when a freely estimated model across the two groups was analyzed $(\mathrm{CFI}=0.942$; $\mathrm{SRMR}=0.080$; RMSEA $=0.048)$. Furthermore, the criteria for metric invariance were identified by comparing the constrained model and the unconstrained model and the result was not different from zero $(P=0.220)$. For measuring the scalar invariance, the same criteria were met as for the intercepts $(P=0.398)$. In addition, these criteria were partially met by un-constraining some paths for some of the items (fulfillment, informational, attitudinal, actionable participation) as they were interpreted differently between male and female. Despite these small differences, we continued with further analyses.

\section{Hypotheses Tests and the Structural Model with Results}

We utilized structural equation modeling (SEM) to simultaneously estimate the hypothesized relationships in the second-order constructs and for the relationships between the constructs, as will be explained below. The analysis revealed that goodness of fit indices $(\mathrm{CFI}=0.940$; $\mathrm{SRMR}=0.085$; RMSEA $=0.061$ ) (see Table 5) prominently exceeded the threshold values thus giving plausible interpretations of the structures underlying the data (Bagozzi and Yi 1988; Roman and Cuestas 2008). Moreover, the Chi square $\left(\chi^{2}\right) / d f$ value was 2.67 , which indicates a very good fit of the model, as the optimal value needs to be between 1 and 3 (Fornell and Larcker 1981). $R^{2}$ values denote the percentage of variance explained for the dependent variables. These values also indicate the predictive power of the exogenous constructs on endogenous variables. For instance, $25 \%$ of the variance is explained in the consumers' ethical perceptions of sharing economy platforms. Moreover, 53\% of the variance is explained in the consumers' value co-creation intentions on sharing economy platforms. CEPSEP as a second-order construct turned out to be the most important factor in the enhancement of the consumers' value co-creation intentions on SEPs (Table 6). In addition, the current study strengthens the use of second-order construct of CEPSEP by explaining the variance in the value co-creation intentions which is $53 \%$. We also found complementary partial mediation 


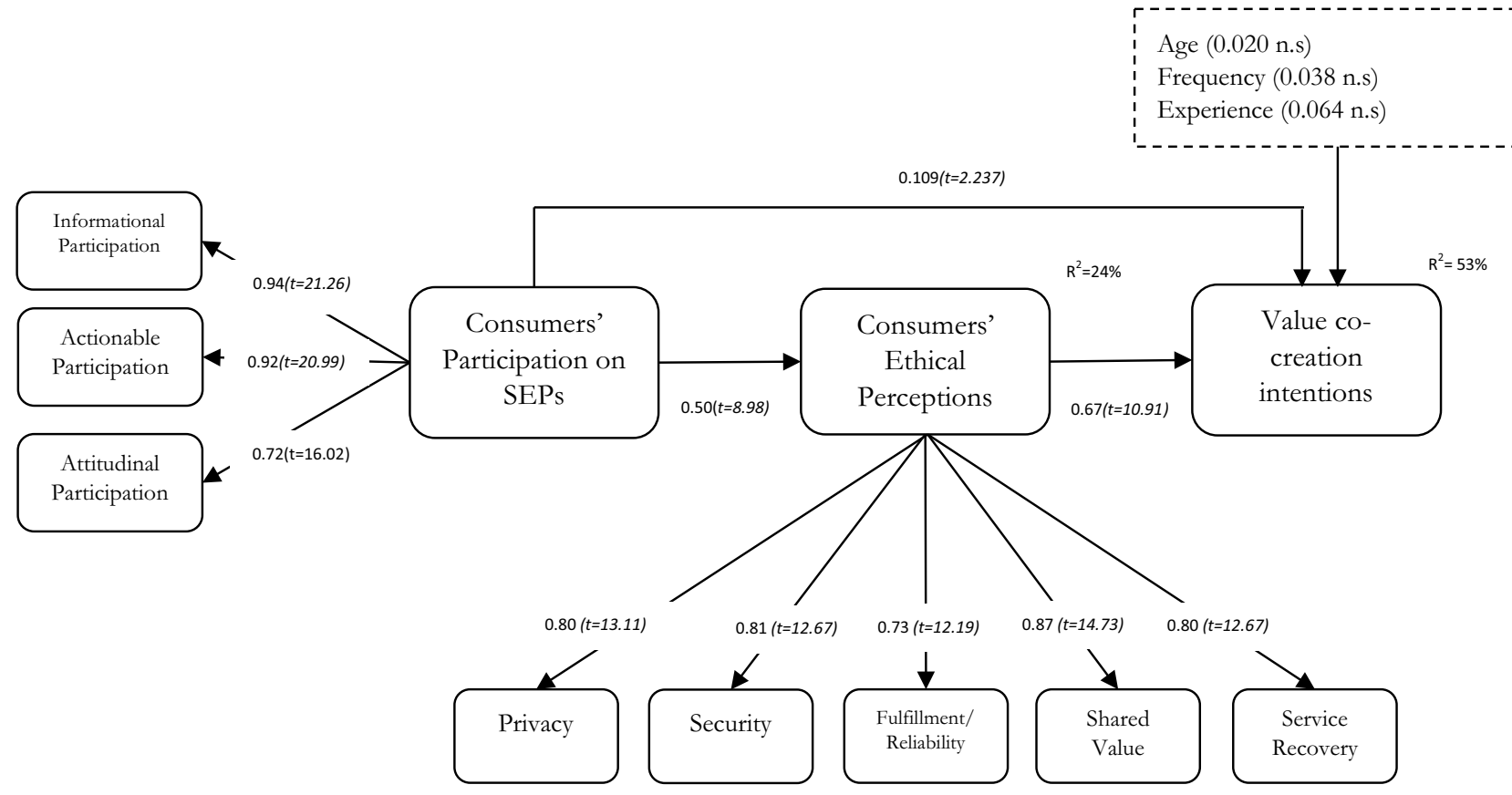

Fig. 2 Structural model with results

of CEPSEP between the consumers' participation and cocreation intentions.

First, as our initial confirmatory factor analyses revealed that the endogenous variable of non-deception (H1f) had a non-significant relationship with the exogenous variable, the second-order construct CEPSEP of non-deception was excluded from further analysis. Thus, in our model CEPSEP is a second-order construct comprising of the five dimensions: privacy (H1a), security (H1b), fulfillment/reliability (H1c), shared value (H1d), service recovery (H1e). All these five endogenous latent factors also had strong standardized co-efficient values as shown in Fig. 2. In conclusion, hypotheses H1a, H1b, H1c, H1d and H-e are supported whilst H1f is not supported.

Second, our model contained consumer participation as a second-order construct with three dimensions: informational participation (H2a), attitudinal participation $(\mathrm{H} 2 \mathrm{~b})$ and actionable participation (H2c). On the basis of strong positive and significant co-efficient values, $\mathrm{H} 2 \mathrm{a}, \mathrm{H} 2 \mathrm{~b}$ and $\mathrm{H} 2 \mathrm{c}$ are supported.

Third, the model contained relationships between consumer participation and consumers' ethical perceptions (H3) ( $\beta=0.502, P<0.01$ ); the consumers' ethical perceptions and value co-creation intentions (H4) $(\beta=0.67, P<0.01)$; as well as consumer participation and value co-creation intentions (H5) $(\beta=0.109, P<0.025)$. Thus, H3, H4 and H5 were supported. Additionally, we controlled the model as was done before (see, e.g., Liébana-Cabanillas and Alonso-DosSantos 2017; McCole et al. 2010; Nadeem et al. 2015) with age $(\beta=0.020, P<0.508)$, frequency $(\beta=0.038, P<0.992)$ and experience $(\beta=0.064, P<0.090)$, and none of them were strongly supported.

In order to further examine both the construct of consumer ethical perception and its role in relation to consumer participation and value co-creation intentions, we tested a rival model without treating CEPSEP as a second-order construct, that is, each of its dimensions were considered as an individual factor (see Fig. 3 in Appendix). The goodness of fit indices of the model were not in accordance with strong threshold values $(\mathrm{CFI}=0.892$; $\mathrm{SRMR}=0.098$; RMSEA = 0.082). Therefore, the current study provides strong support for using CEPSEP as a second-order construct comprising of five dimensions, along with its essential role between consumer participation and value co-creation intentions on SEPs.

\section{Mediation Tests}

Following the procedure suggested by Zhao et al. (2010) to identify mediation effects, a bootstrapping procedure of the specific indirect effects was run in order to identify unique indirect effects for every possible mediation (Gaskin and Lim 2018). The direct effect of consumers' participation on value co-creation intentions was significant and positive $(\beta=0.109, P<0.000)$. Moreover, consumers' ethical perceptions act as a mediator between the aforementioned relationship $(\beta=0.394, P<0.000)$ (Table 7). The model fit values for mediation model are as follows: $\chi^{2}=719.376$, 
Table 7 Mediation tests

\begin{tabular}{lllll}
\hline Parameter & Standardized Estimate & Lower & Upper & $P$ \\
\hline PARCP $\times$ CEPSEP $\times$ COCRE & $0.394 * * *$ & 0.309 & 0.503 & .001 \\
\hline
\end{tabular}

PARCP consumers' participation on sharing economy platforms, CEPSEP consumers' ethical perceptions of sharing economy platforms, COCRE value co-creation intentions

*** $P<0.001 ; * * P<0.010 ; * P<0.050 ;{ }^{\dagger} P<0.100$

Table 8 Multigroup gender difference analysis

\begin{tabular}{llllllll}
\hline Model & DF & CMIN & $P$ & NFI delta-1 & IFI delta-2 & RFI rho-1 & TLI rho-2 \\
\hline Structural weights & 27 & 41.727 & 0.035 & 0.005 & 0.005 & -0.001 & -0.001 \\
\hline
\end{tabular}

$\mathrm{df}=282, \mathrm{GFI}=0.882, \mathrm{AGFI}=0.854, \mathrm{CFI}=0.945$, $\mathrm{NFI}=0.912, \mathrm{RFI}=0.899, \mathrm{IFI}=0.945, \mathrm{TLI}=0.936$, RMSEA $=0.059$, and SRMR $=0.077$. The partial mediation effect of consumers' ethical perceptions indicates that, despite consumers' participation in SEPs, consumers' ethical perceptions depend on their level of participation in SEPs, which thereby facilitates value co-creation intentions. This means that if consumers are not involved in participating in SEPs at a high level, they will be unable to figure out how (un)ethical the SEP is, eventually not drawing positive perceptions about the ethicality of the sharing economy platform. In our study, both direct and indirect effects are significant and positive, indicating that consumers' participation on SEPs has a direct impact on their value co-creation intentions and this effect is also mediated by consumers' ethical perceptions of SEPs. These effects confirm the role of ethical perceptions as a partial mediator.

Moreover, Zhao et al. (2010) suggested three categories of mediation, i.e., complementary mediation, competitive mediation and indirect only/full mediation. Complementary mediation occurs when the direct affect is significant and points in the same direction as the indirect effect. Competitive mediation occurs when the direct effect is significant but points in the opposite direction. Indirect only/full mediation occurs when the direct effect is insignificant, and the indirect effect is significant. In current study, the direct effect of the consumers' participation on the consumers' value co-creation intentions was positive and significant. Therefore, we found complementary mediation of consumer ethical perceptions, which occurs when the direct affect is significant and points in the same direction as the indirect effect (Zhao et al. 2010).

\section{MultiGroup Gender Differences}

With regards to identifying multigroup (male and female) differences, we found that there were no differences different between groups when testing the causal model. Unlike previously (Hajli and Lin 2016), there were no differences in gender which can also be explained through the fact that online gender gap is diminishing (Nadeem et al. 2015), and in new sharing economy platform contexts gender analysis is still at an early stage. However, at the local level (for some paths), we found significant differences between male and female responses, but we did not investigate them further as the global (goodness of fit indices) tests did not fulfill the criteria (Table 8).

\section{Discussion and Implications}

\section{Discussion}

The aim of this study was to create a framework to explore the role of consumers' ethical perceptions in relation to their participation and intention to co-create value on SEPs, and to test the framework empirically. We endeavored to answer the following research questions: (1) What are the dimensions of consumers' ethical perceptions of SEPs? and (2) What is the role of ethical perceptions in relation to consumer participation and value co-creation intentions on SEPs? We developed our research model with help of the theoretical insights from the literature on marketing ethics (Agag 2019; Bush et al. 2000; Cheng et al. 2014; Laczniak and Murphy 2019; Roman and Cuestas 2008), value co-creation (Vargo and Lusch 2004, 2008; Vargo et al. 2008), and the social psychological stream of the uses and gratifications theory (Katz et al. 1973). We have derived the following insights from our empirical analysis.

First, our findings show that on SEPs, consumers' ethical perceptions can be considered as a second-order construct that contains five factors: privacy, security, fulfillment, service recovery, and shared value. Each of these factors is an essential aspect of the consumers' ethical perception in the context of SEPs. Previous research has successfully concluded that online consumers' ethical perceptions can be considered as a four (Roman 2007), five (Cheng et al. 2014), or 
six (Agag et al. 2016) factor construct. Privacy, security and fulfillment in our construct are similar to those suggested by all the researchers above, whilst service recovery and shared value have been recognized by Cheng et al. (2014) and Agag et al. (2016). Somewhat surprisingly, non-deception, which we originally included in our model, and the existence of which all the e-commerce researchers above have confirmed, proved to be non-significant in our analyses. We assume that in SEPs where a service provider can either be a company or an individual consumer, the consumers' concern that the service provider would engage in fraud, for instance, by misrepresenting information or through the unreliable delivery of goods and services, may expand from companies to all peers who operate on the platform, and this may easily result in perceptions of deception. Yet, our data showed that the construct of nondeception was not part of the consumers' ethical perception. We offer two possible explanations for this. Firstly, in comparison to traditional e-commerce platforms, the concept of non-deception loses its original meaning in SEPs where consumer participation is at the center of the platform, rather than company functions. Secondly, it is highly likely that although the concept is non-significant for some consumers, it still may be significant for others, and we were unable to confirm the role of the concepts due to this heterogeneity. Thus, our study supports Mittendorf (2016), who asserts that findings from e-commerce context cannot as such be adapted in the context of sharing economy.

Second, as we initially proposed, our findings verify that ethical perceptions mediate the relationship between consumer participation and their intention to co-create value on SEPs. Although our model and context are novel, our findings are in line with the existing research in many respects. Our findings suggest that an increase in participation on SEPs leads to an increase in the positive ethical perceptions of those SEPs. This finding fits well with existing notions that consumers enthusiastically adopt SEP services and products (see e.g., Zervas et al. 2017), yet the more they participate, the more they recognize that ethical misbehavior (Citera et al. 2005; Dinev and Hart 2006; Malhotra et al. 2004) is likely to happen on online platforms. Additionally, our findings reveal that consumers' ethical perceptions of SEPs influence their value co-creation intentions. This finding is also logical, as researchers have previously revealed that consumers' participation in co-creation activities is enhanced when businesses behave in accordance with values that motivate consumers (Williams and Aitken 2011), such as displaying good ethics (Martinez-Canas et al. 2016). In other words, the finding is in line with Martinez-Canas et al. (2016), who propose that consumers tend to obtain more value from participation, when ethical products and services are involved in the co-creation process.

Third, in terms of the direct relationship between consumer participation and the intention to co-create value, our findings are in line with Hajli et al. (2017) who propose that consumers' participation in SEPs is an important element of value co-creation. It is also in line with extant research (Chae and Ko 2016; Kamboj et al. 2018) which proposes that consumer participation on SEPs refers to an effort to achieve value co-creation. Additionally, our finding is in line with existing research that has revealed consumer participation on online platforms can result in value creation (Schau et al. 2009), value co-creation (Martinez-Canas et al. Martinez-Cañas et al. 2016), and brand co-creation (Kamboj et al. 2018).

Finally, the findings of this study confirm that consumer participation is a second-order construct consisting of informational participation, actionable participation and attitudinal participation on SEPs. The finding is logical, because, in their essence, SEPs exist because of the active online participation of consumers. Attaining information about the possible SEP products or services, participating in SEPs' activities, and hence the emergence of a positive or negative psychological tendency based on the SEPs' performance are all central aspects when operating on SEPs (Kamboj et al. 2018; Kamboj and Rahman 2017; Kamboj and Sarmah 2018). This result extends the existing research, which has considered consumer participation on a single item (Algesheimer et al. 2005) or two item (Kang et al. 2014; Wang et al. 2015) scale, and confirms that a multidimensional perspective (Carlson et al. 2018; Chae et al. 2015, 2016), and specifically the scale developed by Kamboj and Sarmah (2018), is suitable for measuring consumers' participation in the context of SEPs.

\section{Theoretical Implications}

The study advances the extant research on ethics in the context of the sharing economy in three ways. First, the current study gives a profound understanding of a multidimensional construct of consumers' ethical perceptions of SEPs. To the best knowledge of the authors of this study, the current study is the first to examine consumers' ethical perceptions in the context of SEPs in general and as a second-order construct in particular, thereby contributing to the marketing ethics literature, which has not yet tapped into this new phenomenon of sharing economy. Several researchers (Agag et al. 2016; Agag 2019; Cheng et al. 2014; McIntyre et al. 1999; Reidenbach and Robin 1990; Roman and Cuestas 2008) have recognized ethics is a highly abstract, multidimensional and complex construct, and many researchers (e.g., Agag et al. 2016, 2019; Cheng et al. 2014; Roman 2007) have already examined consumers' ethical perceptions in online environments. Empirical research on the role of ethics in the sharing economy has mainly focused on privacy concerns in the information systems domain (see e.g., Lutz et al. 2018; Teubner and Flath 2019), yet has largely overlooked other ethical 
constructs such as security, fulfillment/reliability, shared value, non-deception, and service recovery typically studied in the e-commerce domain. Therefore, providing a workable second-order construct of consumers' ethical perceptions of SEPs advances the literature on marketing and business ethics in general and the literature on ethics in SEPs (GonzalezPadron 2017; Teubner and Flath 2019) particularly.

Second, the study is the first to create an empirically validated framework that helps explain the role of consumers' ethical perceptions in their participation and intention to co-create value specifically on SEPs. By integrating concepts from UGT in social psychology; marketing and business ethics literature; and SD-logic, the current study contributes to the sharing economy literature by focusing on the role of ethical perceptions as a mediator between consumers' participation and their value co-creation intentions, thereby expanding the embryonic research on SEPs. Although previous literature on the sharing economy has revealed why people participate in collaborative consumption (Hamari et al. 2016), what makes people use the SEPs again (Möhlman 2015), and what the inhibiting factors of using SEPs are (Zach et al. 2018) in disciplines such as information systems and consumer behavior, the authors of this study are not aware of any scientific contribution that explains the role of consumers' ethical perceptions in their participation and intention to co-create value on SEPs. Thereby the current study significantly contributes to the literatures on marketing ethics and sharing economy. Several authors (e.g., Perren and Kozinets 2018; Sutherland and Jarrahi 2018) have strongly urged that ethical aspects related to SEPs have been underexplored, hence this study answers this call. In addition, the study advances the literature on consumer participation in the co-creation of value (Martinez-Cañas et al. 2016) and value creation on SEPs (Camilleri and Neuhofer 2017; Zhang et al. 2018), both of which have remained under-researched topics. Accordingly, the current study significantly contributes to the literatures on marketing ethics and sharing economy and the current study serves as a foundational platform for the study of ethics, participation, and value co-creation on SEPs.

Third, this study is the first to confirm that consumer participation is also a second-order construct in the context of SEPs, thereby contributing the emergent literature on the topic. Researchers (e.g., Algesheimer et al. 2005; Carlson et al. 2018; Kamboj and Sarmah 2018; Kang et al. 2014; Wang et al. 2015) have a long tradition of examining consumer participation in online environments, yet no research has examined consumers' participation on SEPs. We extended the existing literature on SEPs by adopting the phenomenon of consumers' participation from the literature on online environments and confirmed the structure of the concept empirically. Thus, the current study provides a significant contribution to literature on the sharing economy.
With these contributions, we have partly resolved the limitations that have been frequently formulated by previous research, specifically urging on ethicality in sharing economy literature (Dakhlia et al. 2016; Gonzalez-Padron 2017; Hawlitschek et al. 2016; Laczniak and Murphy 2019; Lutz et al. 2018; Ma et al. 2017; Mittendorf 2016; Perren and Kozinets 2018; Sutherland and Jarrahi 2018; Teubner and Flath 2019; Zach et al. 2018). The current study is one of the pioneering studies examining consumers' ethical perceptions of SEPs, and it's relationship with consumers's participation and value co-creation intentions thereby incrementally adding to a growing body of knowledge.

\section{Managerial Implications}

The present study may operate as a first step in SEP ethics management. In the context of SEPs, it becomes paramount for not only the SEP service providers themselves but also all users to understand how consumers' ethical perceptions form and how they influence consumers' value co-creation intentions on these platforms.

Our results show that consumer participation plays an important role in explaining the formation of the consumers' ethical perceptions of the platform. In other words, the more consumers participate, the more they become aware of a variety of ethical aspects that relate to operating on the platform. In terms of ethical aspects, taking care of traditional ethical concerns such as privacy and security becomes inadequate in the context of sharing economies. Instead, several new ethical aspects need to be acknowledged. These include aspects such as reliability in the form of accurately displaying services, as well as the consumers' perception that the provider's values are in line with their own values, and taking care that the actions the service provider executes in cases of service failures are implemented well, and responses to customer complaints are carried out promptly. These findings help service providers and all users better understand the role and importance of the multidimensionality of consumers' ethical perceptions. This, hopefully, further enables SEPs to prioritize their resources and reduce the potential risks, as well as encourages them to better take care of possible challenges, such as data breaches and deception (e.g.; Laczniak and Murphy 2019; Newcomer 2017; TheGuardian 2018), which have recently become surprisingly common.

As the current study shows, the ethical aspects above are essential as they directly influence the intentions of consumers to engage in co-creation on the platform. In other words, these ethical aspects have an influence on how willing consumers are to share their experiences and give advice to others on the platform. Furthermore, even more importantly, ethical perceptions impact consumers' willingness to buy products and services through those platforms. As consumer participation and willingness to co-create are essential aspects of the sharing 
economy, the mediating role of the ethical perceptions of the consumers should not be underestimated.

\section{Limitations and Further Research Directions}

Despite the contributions of this study, some limitations need to be acknowledged. First, the majority of our respondents represented Generation Y consumers who used SEPs monthly or even weekly and had 2-4 years of experience of using SEPs, mainly Uber. Specifically focusing on different consumer segments, such as Generation X or elderly people or those who have less than 2 years of experience of using an SEP or those who use other SEPs, could provide additional insights of the phenomenon.

Second, some of our constructs were measured with a small number of items. Although many researchers recognize that this is an acceptable way of conducting SEM research, the approach has also received criticism. Therefore, further testing of the constructs with retaining as many items as possible is recommended. Third, the role of the factor non-deception seems to require further research. Although non-deception has been revealed as an essential part of consumers' ethical perceptions in other online contexts, our results revealed that it was non-significant in SEP. As the use of SEPs is constantly increasing (Zervas et al. 2017) and thus the possibilities for data breaches and deception (Laczniak and Murphy 2019; Newcomer 2017; TheGuardian 2018) may also increase, consumer perceptions of non-deception may change very quickly. Further examination of the role of non-deception could include replicating the current study in the near future, or focus on examining whether consumer perceptions differ for different unobservable groups of respondents, i.e., latent classes (see, e.g., Nadeem et al. 2017).

Acknowledgments Open access funding provided by University of Oulu. The authors would also like to thank the Section Editor and three anonymous reviewers whose valuable comments enabled us to improve the quality of this manuscript significantly.

Funding This study was not been funded by any grant.

\section{Compliance with Ethical Standards}

Conflict of interest All authors declare that they have no conflict of interest.

Ethical Approval All procedures performed in studies involving human participants were in accordance with the ethical standards of the institutional and/or national research committee and with the 1964 Helsinki declaration and its later amendments or comparable ethical standards.

Informed Consent Informed consent was obtained from all individual participants included in the study.

Open Access This article is distributed under the terms of the Creative Commons Attribution 4.0 International License (http://creativeco mmons.org/licenses/by/4.0/), which permits unrestricted use, distribution, and reproduction in any medium, provided you give appropriate credit to the original author(s) and the source, provide a link to the Creative Commons license, and indicate if changes were made.

\section{Appendix}

See Fig. 3.

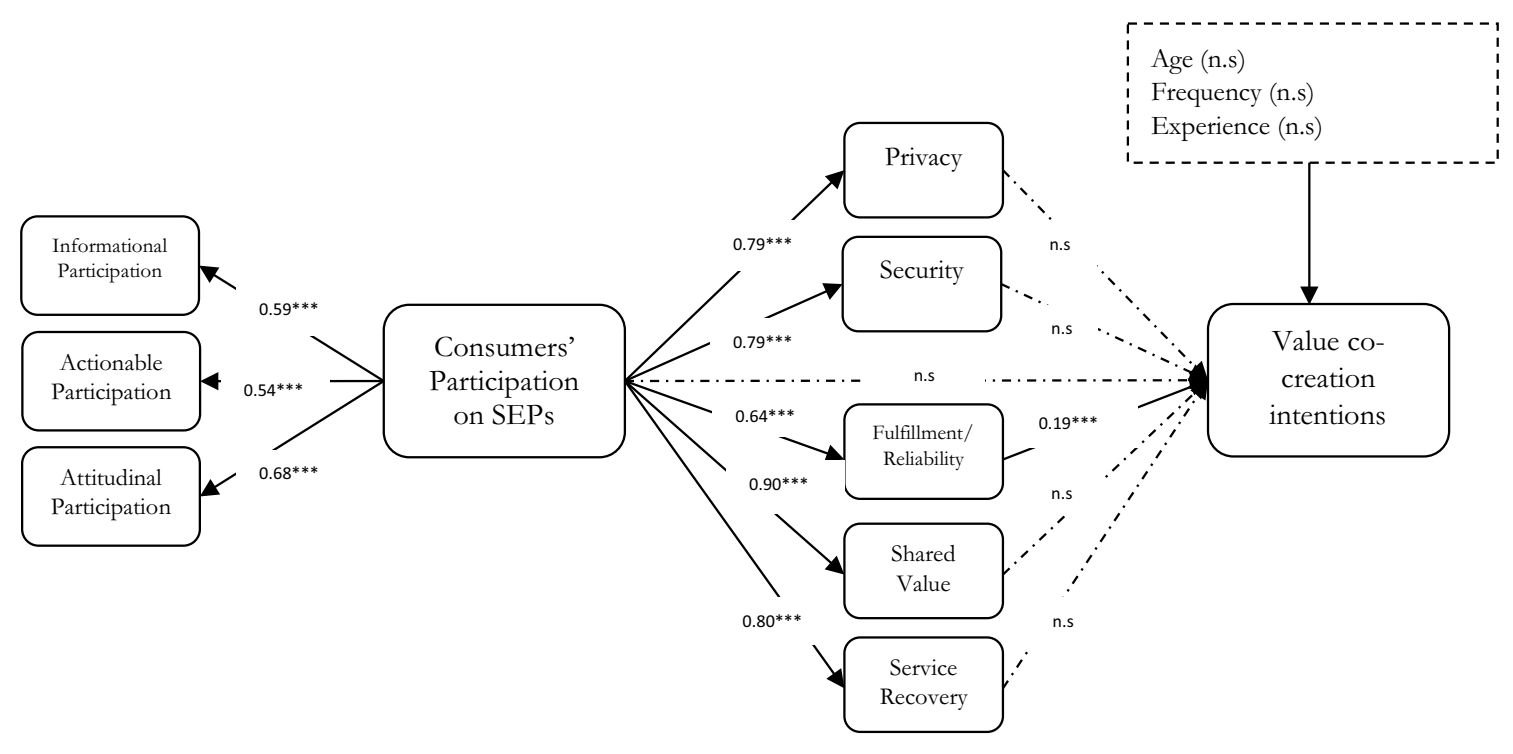

Fig. 3 Rival model. $* * * P<0.001 ; * * P<0.010 ; * P<0.050 ;{ }^{\dagger} P<0.100 ;(\mathrm{CFI}=0.892$; SRMR $=0.098$; RMSEA $=0.082)$ 


\section{References}

Abela, A. V., \& Murphy, P. E. (2008). Marketing with integrity: Ethics and the service-dominant logic for marketing. Journal of the Academy of Marketing Science, 36(1), 39-53.

Acquisti, A., Taylor, C., \& Wagman, L. (2016). The economics of privacy. Journal of Economic Literature, 54(2), 442-492.

Agag, G. (2019). E-commerce ethics and its impact on buyer repurchase intentions and loyalty: An empirical study of small and medium Egyptian businesses. Journal of Business Ethics, 154(2), 389-410.

Agag, G., El-masry, A., Alharbi, N. S., \& Ahmed Almamy, A. (2016). Development and validation of an instrument to measure online retailing ethics: Consumers' perspective. Internet Research, 26(5), 1158-1180.

Algesheimer, R., Dholakia, U. M., \& Herrmann, A. (2005). The social influence of brand community: Evidence from European car clubs. Journal of Marketing, 69(3), 19-34.

Anderson, J. C., \& Gerbing, D. W. (1988). Structural equation modeling in practice: A review and recommended two-step approach. Psychological Bulletin, 103(3), 411.

Bagozzi, R. P., \& Yi, Y. (1988). On the evaluation of structural equation models. Journal of the Academy of Marketing Science, 16(1), 74-94.

Baldwin, C., Hienerth, C., \& Von Hippel, E. (2006). How user innovations become commercial products: A theoretical investigation and case study. Research Policy, 35(9), 1291-1313.

Barry, V. (1979). Moral issues in business. New York: Wadsworth Publishing Co.

Bart, Y., Shankar, V., Sultan, F., \& Urban, G. L. (2005). Are the drivers and role of online trust the same for all web sites and consumers? A large-scale exploratory empirical study. Journal of Marketing, 69(4), 133-152.

Bartels, R. (1967). A model for ethics in marketing. The Journal of Marketing, 31(1), 20-26.

Belk, R. (2014). You are what you can access: Sharing and collaborative consumption online. Journal of Business Research, 67(8), $1595-1600$

Bendapudi, N., \& Leone, R. P. (2003). Psychological implications of customer participation in co-production. Journal of Marketing, 67(1), 14-28.

Bucher, E., Fieseler, C., \& Lutz, C. (2016). What's mine is yours (for a nominal fee)-Exploring the spectrum of utilitarian to altruistic motives for internet-mediated sharing. Computers in Human Behavior, 62, 316-326.

Buhrmester, M., Kwang, T., \& Gosling, S. D. (2011). Amazon's Mechanical Turk a new source of inexpensive, yet high-quality, data? Perspectives on Psychological Science, 6(1), 3-5.

Bush, V. S., Venable, B. T., \& Bush, A. J. (2000). Ethics and marketing on the internet: Practitioners' perceptions of societal, industry and company concerns. Journal of Business Ethics, 23, 237-248.

Cadwalladr, C., \& Graham-Harrison, E. (2018). Revealed: 50 million Facebook profiles harvested for Cambridge Analytica in major data breach. The Guardian, 17, 22.

Camilleri, J., \& Neuhofer, B. (2017). Value co-creation and co-destruction in the Airbnb sharing economy. International Journal of Contemporary Hospitality Management, 29(9), 2322-2340.

Carlson, J., Wyllie, J., Rahman, M. M., \& Voola, R. (2018). Enhancing brand relationship performance through customer participation and value creation in social media brand communities. Journal of Retailing and Consumer Services, 50, 333-341.

Chae, H., \& Ko, E. (2016). Customer social participation in the social networking services and its impact upon the customer equity of global fashion brands. Journal of Business Research, 69(9), 3804-3812.
Chae, H., Ko, E., \& Han, J. (2015). How do customers' SNS participation activities impact on customer equity drivers and customer loyalty? Focus on the SNS services of a global SPA brand. Journal of Global Scholars of Marketing Science, 25(2), 122-141.

Cheng, X., Fu, S., \& Vreede, G.-J. (2018). A mixed method investigation of sharing economy driven car-hailing services: Online and offline perspectives. International Journal of Information Management, 41, 57-64.

Cheng, H. F., Yang, M. H., Chen, K. Y., \& Chen, H. L. (2014). Measuring perceived EC ethics using a transaction-process-based approach: Scale development and validation. Electronic Commerce Research and Applications, 13(1), 1-12.

Citera, M. R., Beauregard, R., \& Mitsuya, T. (2005). Experimental study of credibility in e-negotiations. Psychology \& Marketing, 22(2), 163-179.

Cook, R. D. (1977). Detection of influential observation in linear regression. Technometrics, 19(1), 15-18.

Cova, B., \& Dalli, D. (2009). Working consumers: The next step in marketing theory? Marketing theory, 9(3), 315-339.

Cusumano, M. A. (2015). How traditional firms must compete in the sharing economy. Communications of the ACM, 58(1), 32-34.

Dakhlia, S., Davila, A., \& Cumbie, B. (2016). Trust, but verify: The role of ICTs in the sharing economy. In F. Ricciardi \& A. Harfouche (Eds.), Information and communication technologies in organizations and society (pp. 303-311). Cham: Springer.

Dambrine, B., Jerome, J., \& Ambrose, B. (2015). User reputation: Building trust and addressing privacy issues in the sharing economy. Future of Privacy Forums.

Dillahunt, T. R., \& Malone, A. R. (2015). The promise of the sharing economy among disadvantaged communities. In The proceedings of the 33rd annual ACM conference on human factors in computing systems, Seoul, April 18-23.

Dinev, T., \& Hart, P. (2006). An extended privacy calculus model for e-commerce transactions. Information Systems Research, 17(1), 61-80.

Dwyer, C., Hiltz, S., \& Passerini, K. (2007), Trust and privacy concerns within social networking sites: A comparison of Facebook and MySpace. In Paper presented at the proceedings of the 13th Americas conference on information systems, Keystone, $\mathrm{CO}$, August 9-12.

Einav, L., Farronato, C., \& Levin, J. (2016). Peer-to-peer markets. Annual Review of Economics, 8, 615-635.

Ertz, M., Durif, F., \& Arcand, M. (2016). Collaborative consumption: Conceptual snapshot at a buzzword. Journal of Entrepreneurship Education, 19(2), 1-23.

Featherman, M. S., \& Hajli, N. (2015). Self-service technologies and e-services risks in social commerce era. Journal of Business Ethics, 139(2), 251-269.

Ferrell, O. C., Ferrell, L., \& Sawayda, J. (2015). A review of ethical decision-making models in marketing. In A. Nill (Ed.), Handbook on ethics \& marketing (pp. 38-60). Cheltenham: Edward Elgar Publishing.

Firat, A. F., \& Venkatesh, A. (1993). Postmodernity: The age of marketing. International Journal of Research in Marketing, 10(3), 227-249.

Fornell, C., \& Larcker, D. F. (1981). Structural equation models with unobservable variables and measurement error: Algebra and statistics. Journal of Marketing Research, 18(3), 382-388.

Freestone, O., \& Mitchell, V. W. (2004). Generation Y attitudes towards e-ethics and Internet related misbehaviours. Journal of Business Ethics, 54(2), 121-128.

Gaski, J. F. (1999). Does marketing ethics really have anything to say? A critical Inventory of the literature. Journal of Business Ethics, 18(3), 315-334.

Gaskin, J., \& Lim, J. (2018). Indirect Effects. AMOS Plugin: Gaskination's StatWiki. 
Gonzalez-Padron, T. L. (2017). Ethics in the sharing economy: Creating a legitimate marketing channel. Journal of Marketing Channels, 24(1-2), 84-96.

Gronroos, C. (1988). Service quality: The six criteria of good perceived service quality. Review of Business, 9(3), 10

Grönroos, C. (2008). Service logic revisited: Who creates value? And who co-creates? European Business Review, 20(4), 298-314.

Hair, J. F., Jr., Matthews, L. M., Matthews, R. L., \& Sarstedt, M. (2017). PLS-SEM or CB-SEM: Updated guidelines on which method to use. International Journal of Multivariate Data Analysis, 1(2), 107-123.

Hajli, N. (2018). Ethical environment in the online communities by information credibility: A social media perspective. Journal of Business Ethics, 149(4), 799-810.

Hajli, N., \& Lin, X. (2016). Exploring the security of information sharing on social networking sites: The role of perceived control of information. Journal of Business Ethics, 133(1), 111-123.

Hajli, N., Shanmugam, M., Papagiannidis, S., Zahay, D., \& Richard, M. O. (2017). Branding co-creation with members of online brand communities. Journal of Business Research, 70(1), 136-144.

Hamari, J., Sjöklint, M., \& Ukkonen, A. (2016). The sharing economy: Why people participate in collaborative consumption. Journal of the Association for Information Science and Technology, 67(9), 2047-2059.

Hawlitschek, F., Teubner, T., \& Gimpel, H. (2016). Understanding the sharing economy-Drivers and impediments for participation in peer-to-peer rental. In Proceedings of the 2016 49th Hawaii International Conference on System Sciences (HICSS) (pp. 4782-4791). IEEE.

Hellwig, K., Morhart, F., Girardin, F., \& Hauser, M. (2015). Exploring different types of sharing: A proposed segmentation of the market for "sharing" businesses. Psychology \& Marketing, 32(9), 891-906.

Hennig-Thurau, T., Malthouse, E. C., Friege, C., Gensler, S., Lobschat, L., Rangaswamy, A., et al. (2010). The impact of new media on customer relationships. Journal of Service Research, 13(3), 311-330.

Horton, J. J., Rand, D. G., \& Zeckhauser, R. J. (2011). The online laboratory: Conducting experiments in a real labor market. Experimental Economics, 14(3), 399-425.

Hu, L., \& Bentler, P. M. (1999). Cutoff criteria for fit indexes in covariance structure analysis: Conventional criteria versus new alternatives. SEM, 6(1), 1-55.

Huang, R., Kim, H., \& Kim, J. (2013). Social capital in QQ China: Impacts on virtual engagement of information seeking, interaction sharing, knowledge creating, and purchasing intention. Journal of Marketing Management, 29(3-4), 292-316.

Huang, E., \& Liu, C. C. (2010). A study on trust building and its derived value in $\mathrm{C} 2 \mathrm{C}$ e-commerce. Journal of Global Business Management, 6(1), 1.

Ind, N., Iglesias, O., \& Schultz, M. (2013). Building brands together: Emergence and outcomes of co-creation. California Management Review, 55(3), 5-26.

Kamboj, S., \& Rahman, Z. (2017). Measuring customer social participation in online travel communities: Scale development and validation. Journal of Hospitality and Tourism Technology, 8(3), 432-464.

Kamboj, S., \& Sarmah, B. (2018). Construction and validation of the customer social participation in brand communities scale. Internet Research, 28(1), 46-73.

Kamboj, S., Sarmah, B., Gupta, S., \& Dwivedi, Y. (2018). Examining branding co-creation in brand communities on social media: Applying the paradigm of Stimulus-Organism-Response. International Journal of Information Management, 39, 169-185.
Kang, J., Tang, L., \& Fiore, A. M. (2014). Enhancing consumer-brand relationships on restaurant Facebook fan pages: Maximizing consumer benefits and increasing active participation. International Journal of Hospitality Management, 36, 145-155.

Katz, E., Blumler, J. G., \& Gurevitch, M. (1973). Uses and gratifications research. The Public Opinion Quarterly, 37(4), 509-523.

Khan, M. L. (2017). Social media engagement: What motivates user participation and consumption on YouTube? Computers in Human Behavior, 66, 236-247.

Koh, J., \& Kim, Y. G. (2004). Knowledge sharing in virtual communities: An e-business perspective. Expert Systems with Applications, 26(2), 155-166.

Krause, A. E., North, A. C., \& Heritage, B. (2014). The uses and gratifications of using Facebook music listening applications. Computers in Human Behavior, 39, 71-77.

Laczniak, G. R., \& Murphy, P. E. (2019). The role of normative marketing ethics. Journal of Business Research, 95, 401-407.

Lamb, R., \& Kling, R. (2003). Reconceptualizing users as social actors in information systems research. MIS Quarterly, 27, 197-236.

Liébana-Cabanillas, F., \& Alonso-Dos-Santos, M. (2017). Factors that determine the adoption of Facebook commerce: The moderating effect of age. Journal of Engineering and Technology Management, 44, 1-18.

Limayem, M., \& Cheung, C. M. (2011). Predicting the continued use of Internet-based learning technologies: The role of habit. Behaviour \& Information Technology, 30(1), 1-99.

Limbu, Y. B., Wolf, M., \& Lunsford, D. L. (2011). Consumers' perceptions of online ethics and its effects on satisfaction and loyalty. Journal of Research in Interactive Marketing, 5(1), 71-89.

Livingstone, S. (2004). Media Literacy and the challenge of new information and communication technologies. The Communication Review, 7(1), 3-14.

Lutz, C., Hoffmann, C. P., Bucher, E., \& Fieseler, C. (2018). The role of privacy concerns in the sharing economy. Information, Communication \& Society, 21(10), 1472-1492.

Ma, X., Hancock, J. T., Lim Mingjie, K., \& Naaman, M. (2017). Selfdisclosure and perceived trustworthiness of Airbnb host profiles. In Proceedings of the 2017 ACM conference on computer supported cooperative work and social computing (pp. 2397-2409). ACM.

Macduffie. (2017). Uber's data breach: Can the company coursecorrect?. http://knowledge.wharton.upenn.edu/article/ how-uber-can-come-back-from-a-hack/.

Malhotra, N. K., Kim, S. S., \& Agarwal, J. (2004). Internet users' information privacy concerns (IUIPC): The construct, the scale, and a causal model. Information Systems Research, 15(4), 336-355.

Martinez-Cañas, R., Ruiz-Palomino, P., Linuesa-Langreo, J., \& Blázquez-Resino, J. J. (2016). Consumer participation in cocreation: An enlightening model of causes and effects based on ethical values and transcendent motives. Frontiers in Psychology, 7, 793.

Mason, W., \& Suri, S. (2012). Conducting behavioral research on Amazon's Mechanical Turk. Behavior Research Methods, 44(1), $1-23$.

McCole, P., Ramsey, E., \& Williams, J. (2010). Trust considerations on attitudes towards online purchasing: The moderating effect of privacy and security concerns. Journal of Business Research, 63(9-10), 1018-1024.

McIntyre, F. S. J. L., Thomas, Jr, \& Gilbert, F. W. (1999). Consumer segments and perceptions of retail ethics'. Journal of Marketing Theory \& Practice, 7(2), 43-53.

Merz, M. A., Zarantonello, L., \& Grappi, S. (2018). How valuable are your customers in the brand value co-creation process? The development of a Customer Co-Creation Value (CCCV) scale. Journal of Business Research, 82, 79-89. 
Mittendorf, C. (2016). What trust means in the sharing economy: A provider perspective on Airbnb.com. In Proceedings of the 22nd Americas Conference on Information Systems, San Diego.

Miyazaki, A. D., \& Fernandez, A. (2001). Consumer perceptions of privacy and security risks for online shopping. The Journal of Consumer Affairs, 35(1), 27-44.

Möhlmann, M. (2015). Collaborative consumption: determinants of satisfaction and the likelihood of using a sharing economy option again. Journal of Consumer Behaviour, 14(3), 193-207.

Morgan, R. M., \& Hunt, S. D. (1994). The commitment-trust theory of relationship marketing. The Journal of Marketing, 58(3), 20-38.

Nadeem, W., Andreini, D., Salo, J., \& Laukkanen, T. (2015). Engaging consumers online through websites and social media: A gender study of Italian Generation Y clothing consumers. International Journal of Information Management, 35(4), 432-442.

Nadeem, W., Juntunen, M., \& Juntunen, J. (2017). Consumer segments in social commerce: A latent class approach. Journal of Consumer Behaviour, 16(3), 279-292.

Nambisan, S., \& Nambisan, P. (2008). How to profit from a better' virtual customer environment'. MIT Sloan Management Review, 49(3), 53.

Newcomer, E. (2017). Uber CEO to take leave, have diminished role after scandals," bloomberg (June 13), https://www.bloomberg. com/news/articles/2017-06-13/uber-ceo-to-take-leave-dimin ished-role-after-workplace-scandals.

Nunnally, J. (1978). Psychometric theory (2nd ed.). New York: McGraw-Hill.

OHern, M. S., \& Rindfleisch, A. (2010). Customer co-creation. Review of marketing Research (pp. 84-106). Bingley: Emerald Group Publishing Limited.

Pai, P. Y., \& Tsai, H. T. (2011). How virtual community participation influences consumer loyalty intentions in online shopping contexts: An investigation of mediating factors. Behaviour \& Information Technology, 30(5), 603-615.

Parasuraman, A., Zeithaml, V. A., \& Malhotra, A. (2005). E-S-QUAL: A multiple-item scale for assessing electronic service quality. Journal of Service Research, 7(3), 213-233.

Pavlou, P. A., Liang, H., \& Xue, Y. (2007). Understanding and mitigating uncertainty in online exchange relationships: A principalagent perspective. MIS Quarterly, 31, 105-136.

Payne, A. F., Storbacka, K., \& Frow, P. (2008). Managing the co-creation of value. Journal of the Academy of Marketing Science, 36(1), 83-96.

Perren, R., \& Kozinets, R. V. (2018). Lateral exchange markets: How social platforms operate in a networked economy. Journal of Marketing, 82(1), 20-36.

Peterson, R. A., \& Merunka, D. R. (2014). Convenience samples of college students and research reproducibility. Journal of Business Research, 67(5), 1035-1041.

Podsakoff, P. M., MacKenzie, S. B., Lee, J. Y., \& Podsakoff, N. P. (2003). Common method biases in behavioral research: A critical review of the literature and recommended remedies. Journal of Applied Psychology, 88(5), 879-903.

Prahalad, C. K., \& Ramaswamy, V. (2004). Co-creation experiences: The next practice in value creation. Journal of Interactive Marketing, 18(3), 5-14.

PWC, LLP. (2015). The sharing economy: Consumer intelligence series. http://www.pwc.com/us/en/industry/entertainment-media /publications/consumer-ntelligence-series/assets/pwc-cis-shari ng-economy.pdf.

Raacke, J., \& Bonds-Raacke, J. (2008). MySpace and Facebook: Applying the uses and gratifications theory to exploring friendnetworking sites. Cyberpsychology \& Behavior, 11(2), 169-174.

Ramaswamy, V., \& Ozcan, K. (2016). Brand value co-creation in a digitalized world: An integrative framework and research implications. International Journal of Research in Marketing, 33(1), 93-106.

Reidenbach, R. E., \& Robin, D. P. (1990). Toward the development of a multidimensional scale for improving evaluations of business ethics. Journal of Business Ethics, 9(8), 639-653.

Roman, S. (2007). The ethics of online retailing: A scale development and validation from the consumers' perspective. Journal of Business Ethics, 72(2), 131-148.

Román, S. (2010). Relational consequences of perceived deception in online shopping: The moderating roles of type of product, consumer's attitude toward the internet and consumer's demographics. Journal of Business Ethics, 95(3), 373-391.

Román, S., \& Cuestas, P. J. (2008). The perceptions of consumers regarding online retailers' ethics and their relationship with consumers' general internet expertise and word of mouth: A preliminary analysis. Journal of Business Ethics, 83(4), 641-656.

Sayar, O. (2015). Uber creates value for everyone. https://www.hbs. edu/openforum/openforum.hbs.org/goto/challenge/understand -digital-transformation-of-business/uber-creates-value-for-every one.html.

Schau, H. J., Muñiz, A. M., Jr., \& Arnould, E. J. (2009). How brand community practices create value. Journal of Marketing, 73(5), $30-51$.

Schauster, E., \& Neill, M. (2017). Have the ethics changed? An examination of ethics in advertising and public relations agencies. Journal of Media Ethics, 32(1), 45-60.

Schlegelmilch, B. B., \& Oberseder, M. (2010). Half a century of marketing ethics: Shifting perspectives and emerging trends. Journal of Business Ethics, 93(1), 1-19.

Slee, T. (2017). What's yours is mine: Against the sharing economy. New York: Or Books.

Smith, C. (2016) Who's responsible? The ethics of the sharing economy. https://knowledge.insead.edu/responsibility/whos-respo nsible-the-ethics-of-the-sharing-economy-5034.

Smith, S. M., Roster, C. A., Golden, L. L., \& Albaum, G. S. (2016). A multi-group analysis of online survey respondent data quality: Comparing a regular USA consumer panel to MTurk samples. Journal of Business Research, 69(8), 3139-3148.

Sparks, B. N., \& McColl-Kennedy, J. R. (2001). Justice strategy options for increased customer satisfaction in a services recovery setting. Journal of Business Research, 54(3), 209-218.

Stabrowski, F. (2017). 'People as businesses': Airbnb and urban microentrepreneurialism in New York City. Cambridge Journal of Regions, Economy and Society, 10(2), 327-347.

Statistia (2019). Monthly number of Uber's users worldwide from 2016 to 2018 (in millions). https://www.statista.com/statistics/833743/ us-users-ride-sharing-services/.

Sundararajan, A. (2016). The sharing economy: The end of employment and the rise of crowd-based capitalism. Cambridge: MIT press.

Sutherland, W., \& Jarrahi, M. H. (2018). The sharing economy and digital platforms: A review and research agenda. International Journal of Information Management, 43, 328-341.

Tajvidi, M., Richard, M. O., Wang, Y., \& Hajli, N. (2018). Brand cocreation through social commerce information sharing: The role of social media. Journal of Business Research. https://doi. org/10.1016/j.jbusres.2018.06.008.

Teubner, T., \& Flath, C. M. (2019). Privacy in the sharing economy. Journal of the Association for Information Systems, 20(3), 213-242.

TheGuardian (2018). Uber fined $£ 385,000$ for data breach affecting millions of passengers. https://www.theguardian.com/technology /2018/nov/27/uber-fined-385000-for-data-breach-affecting-milli ons-of-passengers-hacked.

Vargo, S. L., \& Lusch, R. F. (2004). Evolving to a new dominant logic for marketing. Journal of Marketing, 68(1), 1-17. 
Vargo, S. L., \& Lusch, R. F. (2008). Service-dominant logic: Continuing the evolution. Journal of the Academy of Marketing Science, $36(1), 1-10$.

Vargo, S. L., \& Lusch, R. F. (2016). Institutions and axioms: An extension and update of service-dominant logic. Journal of the Academy of Marketing Science, 44(1), 5-23.

Vargo, S. L., Maglio, P. P., \& Akaka, M. A. (2008). On value and value co-creation: A service systems and service logic perspective. European Management Journal, 26(3), 145-152.

Veloutsou, C., \& Moutinho, L. (2009). Brand relationships through brand reputation and brand tribalism. Journal of Business Research, 62(3), 314-322.

Wang, Y., Ma, S. S., \& Li, D. (2015). Customer participation in virtual brand communities: The self-construal perspective. Information \& Management, 52(5), 577-587.

Williams, J., \& Aitken, R. (2011). The service-dominant logic of marketing and marketing ethics. Journal of Business Ethics, 102(3), 439-454.

Wolfinbarger, M., \& Gilly, M. C. (2003). eTailQ: Dimensionalizing, measuring and predicting etail quality. Journal of Retailing, 79(3), 183-198.
Zach, W. Y. L., Chan, T. K. H., Balaji, M. S., \& Chong, A. Y.-L. (2018). Why people participate in the sharing economy: An empirical investigation of Uber. Internet Research, 28(3), 829-850.

Zervas, G., Proserpio, D., \& Byers, J. W. (2017). The rise of the sharing economy: Estimating the impact of Airbnb on the hotel industry. Journal of Marketing Research, 54(5), 687-705.

Zhang, T. C., Jahromi, M. F., \& Kizildag, M. (2018). Value co-creation in a sharing economy: The end of price wars? International Journal of Hospitality Management, 71, 51-58.

Zhao, X. Lynch, Jr, J. G., \& Chen, Q. (2010). Reconsidering Baron and Kenny: Myths and truths about mediation analysis. Journal of Consumer Research, 37(2), 197-206.

Zwass, V. (2010). Co-creation: Toward a taxonomy and an integrated research perspective. International Journal of Electronic Commerce, 15(1), 11-48.

Publisher's Note Springer Nature remains neutral with regard to jurisdictional claims in published maps and institutional affiliations. 